American Journal of Pharmaceutical Education 2019; 83 (1) Article 6457.

\title{
RESEARCH
}

\section{A Thematic Analysis of Pharmacy Students' Experiences of the Undergraduate Pharmacy Degree in Ireland and the Role of Mindfulness}

\author{
Michelle O'Driscoll, MPharm, ${ }^{a}$ Stephen Byrne, PhD, ${ }^{a}$ Maria Kelly, PhD, ${ }^{a}$ Sharon Lambert, PhD, \\ Laura J. Sahm, $\mathrm{PhD}^{\mathrm{a}, \mathrm{c}}$ \\ ${ }^{a}$ School of Pharmacy, University College, Cork, Ireland \\ ${ }^{\mathrm{b}}$ School of Applied Psychology, University College, Cork, Ireland \\ ${ }^{\mathrm{c}}$ Mercy University Hospital, Cork, Ireland \\ Submitted April 11, 2017; accepted February 15, 2018; published February 2019.
}

Objective. To determine pharmacy students' experiences of stress as part of the current pharmacy degree, and to explore the potential of incorporating the principles of mindfulness into course work in the undergraduate degree.

Methods. Undergraduate pharmacy students from the five pharmacy schools in Ireland were invited to participate in focus groups between February and November 2016. Recruitment occurred via emails sent by a school's academic or administrative member. Focus groups were audio recorded, anonymized and transcribed by the corresponding author. Transcripts were analyzed using the Braun and Clarke method of thematic analysis and coded.

Results. Twenty pharmacy students (60\% female) representing all years of study from three of the five pharmacy schools participated across five focus groups. The five key themes that emerged were: so much to do, so little time; the role of lecturers; we are smart people, we want to do well; learning by doing; and mindfulness as a coping tool.

Conclusion. The findings of this study support the hypothesis that students experience stress and would welcome mindfulness-based interventions as a management option in the degree. Specifically, the emphasis that mindfulness places on experiential learning would be well-received by students.

Keywords: pharmacy, stress, student, mindfulness, undergraduate

\section{INTRODUCTION}

Stress, defined as "a mismatch between demands and the perceived ability to cope with these demands," can have a negative impact on the physical health, mental health, and academic performance of health care students. ${ }^{1,2}$ Pharmacy students, in particular, demonstrate higher levels of stress than the general population, regardless of year of study. ${ }^{3,4}$ Furthermore, health care student stress is reportedly linked to subsequent stress as a health care practitioner. ${ }^{5}$ The psychological challenges and responsibilities associated with managing patients as a health care professional can lead to depression and burnout, negatively affecting one's personal well-being. ${ }^{6}$ These findings are concerning because high levels of stress can lead to poor decision-making and compromise patient safety and increase the risk of medication errors. ${ }^{7}$ Mott and colleagues reported that $68 \%$ of 1,737 actively

Corresponding Author: Michelle O’Driscoll, Cavanagh Pharmacy Building, Room UG06, University College Cork, Cork, Ireland. Tel: +353-21-4901656. E-mail: michelle. odriscoll@ucc.ie practicing pharmacists experienced job stress and role overload. ${ }^{8}$ Dowell and colleagues showed that pharmacists were more likely than surgeons or physicians to resign from their jobs due to high stress levels. ${ }^{9}$ To date, the role of mindfulness to increase job satisfaction and patient safety in pharmacists or pharmacy students has not been evaluated.

Mindfulness, defined by Jon Kabat-Zinn, $\mathrm{PhD}$, as "paying attention in a particular way, on purpose, nonjudgmentally, to the present moment" is a practice that changes how one relates to his or her present experience, breaking old habits of worry and rumination and cultivating an attitude of acceptance, rather than struggling to change the unchangeable in life. ${ }^{10} \mathrm{He}$ developed the Mindfulness Based Stress Reduction (MBSR) in 1979 to help hospital patients, ${ }^{11}$ and non-clinical populations, and has produced promising results in educational settings. ${ }^{12,13}$ Pharmacy students have not been represented in the literature to date. Hence, this study's research question was twofold: to determine pharmacy students' experiences of stress as part of the current pharmacy undergraduate degree, and to explore the potential of incorporating the 


\section{American Journal of Pharmaceutical Education 2019; 83 (1) Article 6457.}

principles of mindfulness into course work in the undergraduate degree.

\section{METHODS}

Focus groups were conducted with undergraduate pharmacy students between February and November 2016. All five pharmacy schools in Ireland - University College Cork (UCC), Trinity College Dublin (TCD), Royal College of Surgeons in Ireland (RCSI), Queens University Belfast (QUB) and Ulster University (UU) were invited to participate. All five schools received approval from local ethical committees. The focus group method was chosen as it was felt that participants would interact and prompt thoughts and ideas from one another at a depth that may not occur in an interview setting. ${ }^{14}$

The method of sampling used was purposive and aimed to recruit representatives from all year groups, male and female, with a representation of mature students. Snowball sampling, where existing study subjects recruit future subjects from among their acquaintances, was used in addition when uptake was low. Recruitment occurred through email, sent by each school's academic or administrative member.

A topic guide, as summarized in Table 1 was developed based on a review of previous literature, and discussion among the authors. Immediately after the first focus group met, the guide was reviewed in terms of the wording of the questions. However, no changes were made to the question content so this focus group was included in the final analysis. All questions were used in each session; however, discussions were also allowed to develop naturally to facilitate emergence of unanticipated themes.

The first two focus groups were conducted by two authors of this study. One conducted subsequent focus groups and made reflective notes immediately afterward.

Table 1. Topic Guide for Focus Group Discussions

What skills does the current pharmacy degree develop?

Do you feel that the degree course prepares you mentally for your future profession?

What factors affect your ability to study/perform in college?

What emotions do you experience around examination time/ college deadlines?

Do you think there is a need for mental support/training in the pharmacy degree?

What ways do you think such support could be delivered?

What do you know about mindfulness?

What would help/discourage you from participating in a mindfulness module?

What are your views about online delivery of modules?

What would be the optimum length of time per class? Why?
Focus groups were conducted at the respective pharmacy schools during times convenient to the students. The author who conducted the subsequent focus groups presented herself as a researcher and did not engage in discussion about the topic guide prior to the focus group session to reduce the risk of bias. Demographic information was collected (Table 2). Focus groups were audio recorded and written informed consent was obtained. The author prompted and explored issues that came up where appropriate, allowing for the emergence of unprompted information and themes. Participants were informed that they could request copies of the transcripts of their contribution if desired. The audiotapes were anonymized and transcribed to allow for immersion in the data, and preliminary familiarization with the findings. As per the Francis method of sampling, the final focus groups presented no new themes, and generated no new data at which point it was agreed that data saturation had been achieved.

Transcripts were analyzed using the Braun and Clarke method of thematic analysis, ${ }^{15}$ and coded. Initial familiarization involved several readings of the transcripts, all of which were initially coded. Another author coded a sample of the transcripts. Agreement between coders was high, and disagreement was resolved by discussion. Codes were named in language that remained true to the opinions and experiences of the participants. The codes were then grouped into initial themes, and verified them by reading the corresponding excerpts, and the entire data set again, before naming and defining them. Agreement with LS was reached through discussion at each stage. The study is reported in accordance with the Consolidated Criteria for Reporting Qualitative Research (COREQ) (Appendix 1).

Table 2. General Demographic Characteristics of Pharmacy Student Focus Group Participants $(\mathrm{N}=20)$

\begin{tabular}{lc}
\hline Demographic Characteristics & Proportion \% \\
\hline Age Range & \\
$18-20$ years $(n=7)$ & 35 \\
$21-23$ years $(n=10)$ & 50 \\
$24+$ years $(n=3)$ & 15 \\
Irish $(n=19)$ & 95 \\
Female $(n=12)$ & 60 \\
Year of Study & \\
$1^{\text {st }}$ year $(n=4)$ & 20 \\
$2^{\text {nd }}$ year $(n=5)$ & 25 \\
$3^{\text {rd }}$ year $(n=3)$ & 15 \\
$4^{\text {th }}$ year $(n=8)$ & 40 \\
Previous Pharmacy Experience $(n=9)$ & 45 \\
Previous Degree $(n=1)$ & 5 \\
Children $(n=1)$ & 5 \\
\hline
\end{tabular}




\section{American Journal of Pharmaceutical Education 2019; 83 (1) Article 6457.}

\section{RESULTS}

Twenty pharmacy students ( $60 \%$ female) representing all years of study from three of the five pharmacy schools participated across five focus groups. The average number of participants per focus group was four (ranging from two to seven participants). All but one participant identified themselves as Irish, and two participants held a previous degree. Almost half of participants (45\%) reported having had experience working in a pharmacy setting.

Five key themes emerged through analysis of the transcripts: so much to do, so little time; the role of the lecturer; we're smart people, we want to do well; learning by doing, and mindfulness as a coping tool. The themes are summarized in Figure 1 with specific quotes given in Appendix 2.

The first theme, "so much to do, so little time" was illustrated by the fact that participants' experience is greatly influenced by the workload they need to complete within the pharmacy course, with some participants becoming completely overwhelmed. The pressure to multitask hinders student progress. Multiple simultaneous deadlines increase pressure on students. The workload of the degree leaves very little time for anything else in pharmacy students' lives, and this has a negative impact on other areas. Participants voiced concerns regarding tensions between college and weekend work, or attempts to have a social life as a student. The time pressure that students felt was due to the course work itself, regardless of outside influences. Some students spoke about ceasing optional activities in times of extra pressure (eg, no longer attending sport training in the evenings at home because they were staying in college to study). This was despite the fact that these optional extras often helped to reduce stress.

"The role of the lecturer" in the student experience emerged as another strong theme. Participants felt that lecturers accessible but limited in the support that they can offer. The relationship that the student has with individual lecturers can be variable and affects the student experience. While some students had developed good communication links with lecturers, other felt that a lack of such links hindered them from accessing the support they needed.

"We're smart people, we want to do well" was a theme participants articulated was their fear of failure, and the negative way it affects their performance. This fear includes not achieving high grades, failing a year, and not completing the course. Linked to this fear of failure is the constant comparison to previous personal achievements in school, and a desire not to let anybody down. Students reflected on their experience of the Leaving Certificate (the state examination for school-leavers in Ireland, and the main determinant for entry into third-level education) versus their performance in university end-ofsemester examinations. One participant reported that there is a link between the critical thinking that is required in the course, and the self-criticism that students experience. Coupled with fear of failure as a student was fear of failure in the future as a health care professional. Participants were aware of the responsibilities that they will face as health care professionals, and the impact that their actions will have on patient health. Many vocalized a fear of handling adverse events in the future. Participants

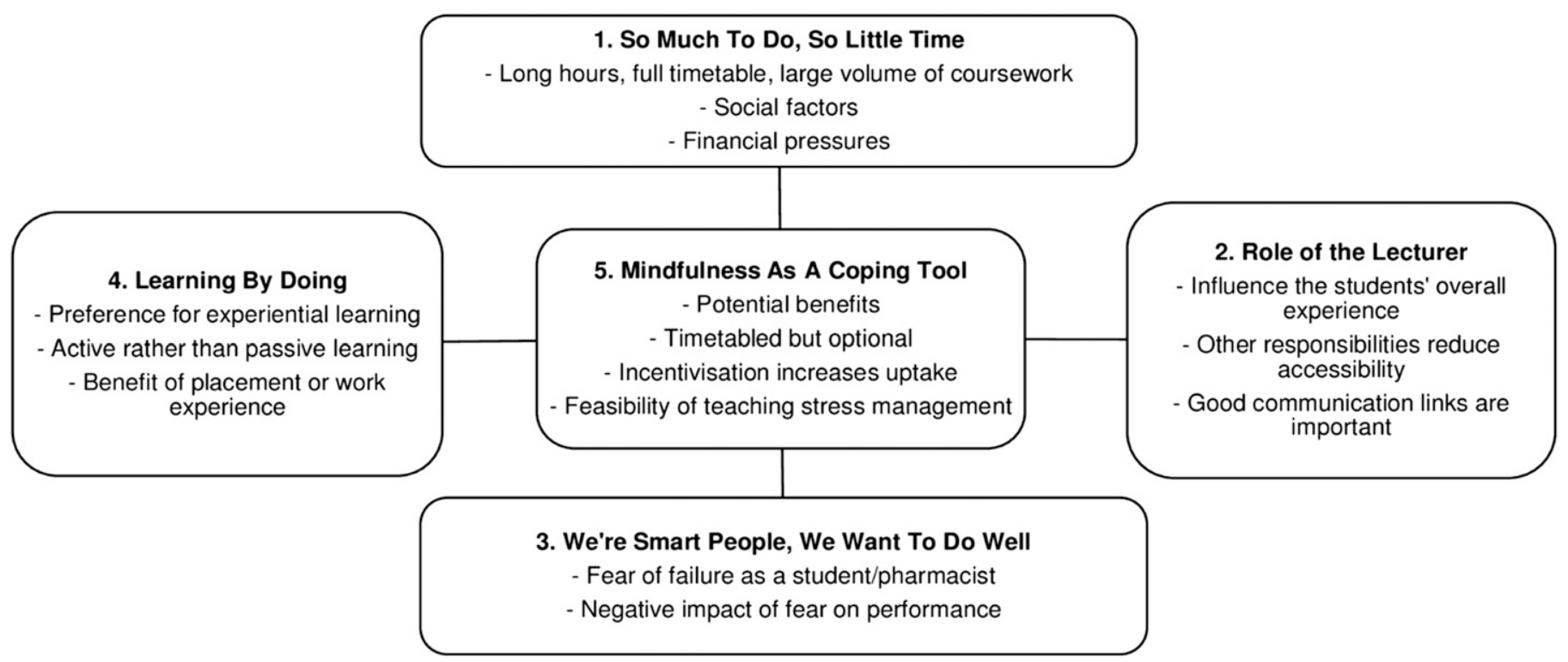

Figure 1. Key Themes of Students' Experiences of the Undergraduate Pharmacy Degree and the Potential Role of Mindfulness. 


\section{American Journal of Pharmaceutical Education 2019; 83 (1) Article 6457.}

attributed recurrent procrastination to this fear of failure, particularly in relation to studying for examinations.

The theme of "learning by doing" was presented. Students articulated the idea that what is taught most effectively during the degree is delivered in a hands-on, practical manner through workshops and tutorials. Participants appreciated experiential learning and gave examples of active skill development, which they spoke of positively. Having the experience of working in a pharmacy setting, while not compulsory, was viewed as being very beneficial in applying what one has learned.

These four themes all fed into the overarching theme of "mindfulness as a coping tool" within the pharmacy degree. There was a generally positive response to the suggestion of introducing a mindfulness course to pharmacy students because of the view that mental training needs to be implemented to benefit future patients and the participants themselves. There was a lack of awareness around supports that were already available within the university setting, and many felt that the available support was not always accessible. Participants valued the idea of stress prevention rather than curing excessive stress.

In general, participants had some knowledge of what mindfulness was, often informed by previous experience of mindfulness in other settings. However, some common misconceptions of mindfulness were voiced also, including the idea that mindfulness is about getting rid of all thoughts and achieving a state of relaxation. Some participants raised questions on the feasibility of "teaching" stress reduction stating that stress is individual and unique to each person, which one needs to experience and handle in their own way. Other stress management strategies such as yoga or sports were mentioned; however, the extra-curricular nature of these activities hindered regular participation. Students reported that no single method will suit everybody.

In terms of how to deliver mindfulness training, participants suggested that a mindfulness course would have to be interactive, with some preferring an online course. Participants reported that the best way to include mindfulness into the curriculum would be as part of the weekly college schedule. In an existing module, clinical pharmacy was the place where students felt it fit best. Early introduction of such training was recommended, although there was ambivalence about whether first-year students would understand the need for this type of learning. It was felt that only students who were stressed would take part, and that this could in itself be a barrier to participation, with people becoming conscious of how they would be perceived if they signed up.

It was conveyed that some incentive would be required for an optional course (eg, certificates or credits). Otherwise, busy schedules and a heavy workload would limit uptake. The standard MBSR course was considered to be too long; a shorter course that could be incorporated into the timetable could be a viable option that students would take part in.

\section{DISCUSSION}

The five themes that emerged from these focus groups provide an insight into the current experience of pharmacy students within the degree, and the role that mindfulness could play in that experience. Challenges that students encounter as part of the degree and fears that they have of future responsibilities as health care professionals could be addressed through mindfulness training.

The preference for experiential learning that these focus groups have highlighted is encouraging, suggesting that an approach such as mindfulness would be well received by pharmacy students because of its experiential nature - it first immerses learners in an experience, and subsequently invites reflection about the experience to develop new skills, or new ways of thinking. ${ }^{16}$ Rather than simply providing students with didactic teaching about stress and well-being, experiential mindfulness techniques may be useful for those who benefit from having hands-on examples to bolster their traditional learning. ${ }^{17}$

These focus groups have provided rich information on the overwhelming pressure that pharmacy students find themselves in when it comes to completing a professional course. This reflects findings from previous research that pharmacy students were the most likely undergraduate group to suffer from stress. ${ }^{3}$ Undergraduate health care students experience moderate levels of stress, with a correlation between stress and academic achievement. ${ }^{18}$ A systematic review conducted by the authors has found benefits of mindfulness for other health care students, which serves as an indicator of effectiveness for this particular cohort. ${ }^{13}$ However, the theme of being overburdened in terms of scheduled coursework cannot be overlooked, and should influence course design. How much time can pharmacy students realistically commit to weekly mindfulness classes and/or daily practice? Such a course would need to fit into an already busy schedule, and be presented as part of the curriculum to achieve buy-in, without being made compulsory.

The importance of the role of the lecturer in relation to student experience presented strongly, which is what the Mindfulness Based Interventions Teaching Assessment Criteria (MBITAC), ${ }^{19}$ the competency guidelines for mindfulness teachers, explicitly addresses. Three of its six domains relate to a teacher's interaction with students, and their engagement with participants, namely embodiment, inquiry and holding of the group. These competencies 


\section{American Journal of Pharmaceutical Education 2019; 83 (1) Article 6457.}

are not highlighted as important in a traditional lecturing role, but could provide students of a mindfulness class with the support and interaction needed to enhance their student experience, cultivating a feeling of support. ${ }^{20}$

The "fear of failure" that participants articulated is reflective of the high academic achievers who sign up for courses such as pharmacy. Pharmacy students have been shown to be highly "achievement" oriented, ${ }^{21}$ which can feed rumination and procrastination. Previous research has found that mindfulness is negatively correlated with rumination. ${ }^{22,23}$ Mindfulness training as part of the pharmacy degree could enable participants "to see more clearly the patterns of the mind, and to recognize when mood is beginning to dip without adding to the problem by falling into analysis and rumination." 24

Participants reported that incorporating mindfulness training into the pharmacy course could be extremely beneficial, due to the challenge of attending extra-curricular activities. While some participants doubted the feasibility of teaching stress reduction through mindfulness, it may be due to their misconception of mindfulness being a process of "emptying your mind." 25 While the stress itself cannot be changed, mindfulness is a way to change one's relationship with stress. Some participants said that "exams are enjoyable," which shows how a person's perception determines their experience, and through mindfulness, pharmacy students' perceptions of stress may be altered in a positive way. This builds on the findings of a previous study that found that test anxiety was associated with students' perception of course load and ability to manage time. ${ }^{26}$

Limitations of this study include the fact that not all pharmacy schools were represented by those who took part in the focus groups. Also, this study was undertaken in Ireland, and may not be fully representative of the experiences or views of pharmacy students in other countries. Nonetheless, this study provides pharmacy educators with valuable insight into the challenges that pharmacy students face and the reaction students may have to incorporating mindfulness into coursework.

\section{CONCLUSION}

This study has provided valuable insight into the perceptions of students of the current pharmacy degree in Ireland, and provides potential benefits and challenges of incorporating mindfulness into coursework. The experiential nature of such a course would suit the active learning and engage teaching methods that pharmacy students seem to respond to best. The content of a mindfulness course could help address some of the pressures of the current program of study.

\section{REFERENCES}

1. Beck DL, Hackett MB, Srivastava R, McKim E, Rockwell B. Perceived level and sources of stress in university professional schools. J Nurs Educ. 1997;36(4):180-186.

2. Misra R, Castillo LG. Academic stress among college students: comparison of American and international students. Int J Stress Manage. 2004;11(2):132-148.

3. Marshall LL, Allison A, Nykamp AA, Lanke S. Perceived stress and quality of life among doctor of pharmacy students. Am J Pharm Educ. 2008;72(6):Article 137.

4. Gallagher CT, Mehta ANV, Selvan R, et al. Perceived stress levels among undergraduate pharmacy students in the UK. Curr Pharm Teach Learn. 2014;6(3):437-441.

5. Collins H, Foote D. Managing stress in veterinary students. $J$ Vet Med Educ. 2005;32(2):170-172.

6. Montero-Marin J, Zubiaga F, Cereceda M, Piva Demarzo MM, Trenc P, Garcia-Campayo J. Burnout subtypes and absence of selfcompassion in primary healthcare professionals: a cross-sectional study. PloS one. 2016;11(6):e0157499.

7. West CP, Huschka MM, Novotny PJ, et al. Association of perceived medical errors with resident distress and empathy: a prospective longitudinal study. JAMA. 2006;296(9):1071-1078. 8. Mott DA, Doucette WR, Gaither CA, Pedersen CA, Schommer JC. Pharmacists' attitudes toward worklife: results from a national survey of pharmacists. J Am Pharm Assoc. 2004;44(3):326-336. 9. Dowell AC, Westcott T, McLeod DK, Hamilton S. A survey of job satisfaction, sources of stress and psychological symptoms among New Zealand health professionals. N Z Med J. 2001(114):540-544. 10. Kabat-Zinn J. Wherever You Go, There You Are: Mindfulness Meditation in Everyday Life. New York, NY: Hyperion; 1994. 11. Kabat-Zinn J, Lipworth L, Burney R. The clinical use of mindfulness meditation for the self-regulation of chronic pain. J Behav Med. 1985;8(2):163-190.

12. Taylor C, Harrison J, Haimovitz K, et al. Examining ways that a mindfulness-based intervention reduces stress in public school teachers: a mixed-methods study. Mindfulness. 2016;7(1):115-129. 13. O'Driscoll M, Byrne S, McGillicuddy A, Lambert S, Sahm LJ. The effects of mindfulness-based interventions for health and social care undergraduate students - a systematic review of the literature. Psychol Health Med. 2017;22(7):851-865.

14. Ritchie J, Lewis J, Nicholls CM, Ormston R, eds. Qualitative Research Practice - A Guide for Social Science Students and Researchers. 2nd ed. Sage Publications; 2013.

15. Braun V, Clarke, V. Using thematic analysis in psychology. Qual Res Psychol. 2006;3(2):77-101.

16. Lewis LH, Williams CJ. Experiential learning: past and present. In Jackson L, Caffarella RS, eds. Experiential Learning: A New Approach. San Francisco, CA: Jossey-Bass; 1994:5-16.

17. Cantor JA. Experiential learning in higher education. ASHE-ERIC higher education report no 7. Washington, DC; 1995.

18. Elias H, Ping WS, Abdullah MC. Stress and academic achievement among undergraduate students in Universiti Putra Malaysia. Procedia - Soc Behav Sci. 2011;29:646-655.

19. Crane RS, Soulsby JG, Kuyken W, et al. The Bangor, Exeter \& Oxford mindfulness-based interventions teaching assessment criteria. 2012.

20. Van Aalderen JR, Breukers WJ, Reuzel RPB, Speckens AEM. The role of the teacher in mindfulness-based approaches: a qualitative study. Mindfulness. 2014;5(2):170-178.

21. Janke KK, Farris KB, Kelley KA, et al. StrengthsFinder signature themes of talent in doctor of pharmacy students in five 


\section{American Journal of Pharmaceutical Education 2019; 83 (1) Article 6457.}

Midwestern pharmacy schools. Am J Pharm Educ. 2015;79(4): Article 49.

22. Brown KW, Ryan RM. The benefits of being present: mindfulness and its role in psychological well-being. J Pers Soc Psychol. 2003; 84(4):822-848.

23. Rood L, Roelofs J, Bögels SM, Nolen-Hoeksema S, Schouten E. The influence of emotion-focused rumination and distraction on depressive symptoms in non-clinical youth: a meta-analytic review. Clin Psychol Rev. 2009;29(7):607-616.
24. Williams JM, Kuyken W. Mindfulness-based cognitive therapy: a promising new approach to preventing depressive relapse. $\mathrm{Br} J$ Psychiatry. 2012;200(5):359-360.

25. Gardner FL, Moore ZE, Marks DR. Rectifying misconceptions: a comprehensive response to "some concerns about the psychological implications of mindfulness: a critical analysis." J Rational-Emotive Cognit-Behav Ther. 2014;32(4):325-344.

26. Sansgiry SS, Sail K. Effect of students' perceptions of course load on test anxiety. Am J Pharm Educ. 2006;70(2):Article 26. 


\section{American Journal of Pharmaceutical Education 2019; 83 (1) Article 6457.}

Appendix 1. Consolidated Criteria for Reporting Qualitative Research (COREQ) Checklist

\begin{tabular}{|c|c|}
\hline Category & Question \\
\hline \multicolumn{2}{|l|}{ Personal Characteristics } \\
\hline Interviewer/facilitator & $\begin{array}{l}\text { Which author/s conducted the interview or } \\
\text { focus group? }\end{array}$ \\
\hline Credentials & $\begin{array}{l}\text { What were the researcher's credentials (eg, } \\
\text { PhD, MD)? }\end{array}$ \\
\hline Occupation & $\begin{array}{l}\text { What was their occupation at the time of the } \\
\text { study? }\end{array}$ \\
\hline Gender & Was the researcher male or female? \\
\hline Experience and training & $\begin{array}{l}\text { What experience or training did the } \\
\text { researcher have? }\end{array}$ \\
\hline \multicolumn{2}{|l|}{ Relationship with } \\
\hline \multicolumn{2}{|l|}{ Participants } \\
\hline Relationship established & $\begin{array}{l}\text { Was a relationship established prior to } \\
\text { study? }\end{array}$ \\
\hline $\begin{array}{l}\text { Participant knowledge of } \\
\text { the interviewer }\end{array}$ & $\begin{array}{l}\text { What did the participants know about the } \\
\text { researcher? }\end{array}$ \\
\hline Interviewer characteristics & $\begin{array}{l}\text { What characteristics were reported about the } \\
\text { interviewer/facilitator? }\end{array}$ \\
\hline
\end{tabular}
interviewer/facilitator?

\section{Theoretical Framework \\ Methodological orientation and theory \\ Participant Selection \\ Sampling \\ Method of approach}

\section{Setting}

Description of sample

Data Collection

\section{Sample size \\ Non-participation}

Setting of data collection

Presence of nonparticipants

Interview guide

What methodological orientation was stated to underpin the study?

How were participants selected?

How were participants approached?

How many participants?

How many people refused to participate or dropped out?

Where was the data collected?

Was anyone else present besides the participants and researchers?

What are the characteristics of the sample?

Were questions, prompts, guides provided by the authors? Was it pilot tested?

Repeat interviews
Were there any repeat interviews?
Investigator 1 conducted all focus groups, with Investigator 2 who also present for the first two focus groups.

Investigator 1 - MPharm

Investigator 2 - MPharm

Qualified pharmacists and research students

Female

Investigator 2 - extensive qualitative research experience

Investigator 1 - trained in conduct, analysis and theory

The researchers introduced themselves before study commencement.

Participants were informed that the primary researcher was conducting the focus group as part of their PhD.

Participants were told that the researcher wanted to see what the current pharmacy degree was like from their experience, and how to better support students.

Analysis was conducted using Braun and Clarke thematic analysis.

Participants were selected using purposive sampling and snowball sampling.

Participants received recruitment emails from a gatekeeper in each pharmacy school inviting them to contact the researcher if they were interested.

Twenty students took part in the focus groups $\mathrm{n} / \mathrm{a}$

Data was collected in a suitable room in the respective pharmacy buildings.

One pharmacy school sent two staff members to sit in on the focus group, but they did not participate in the focus group in any way.

Demographic information is presented in results.

A topic guide was developed by the authors, and piloted on the first focus group. No changes were necessary. This focus group was included in the results.

No 


\section{American Journal of Pharmaceutical Education 2019; 83 (1) Article 6457.}

Appendix 1. (Continued)

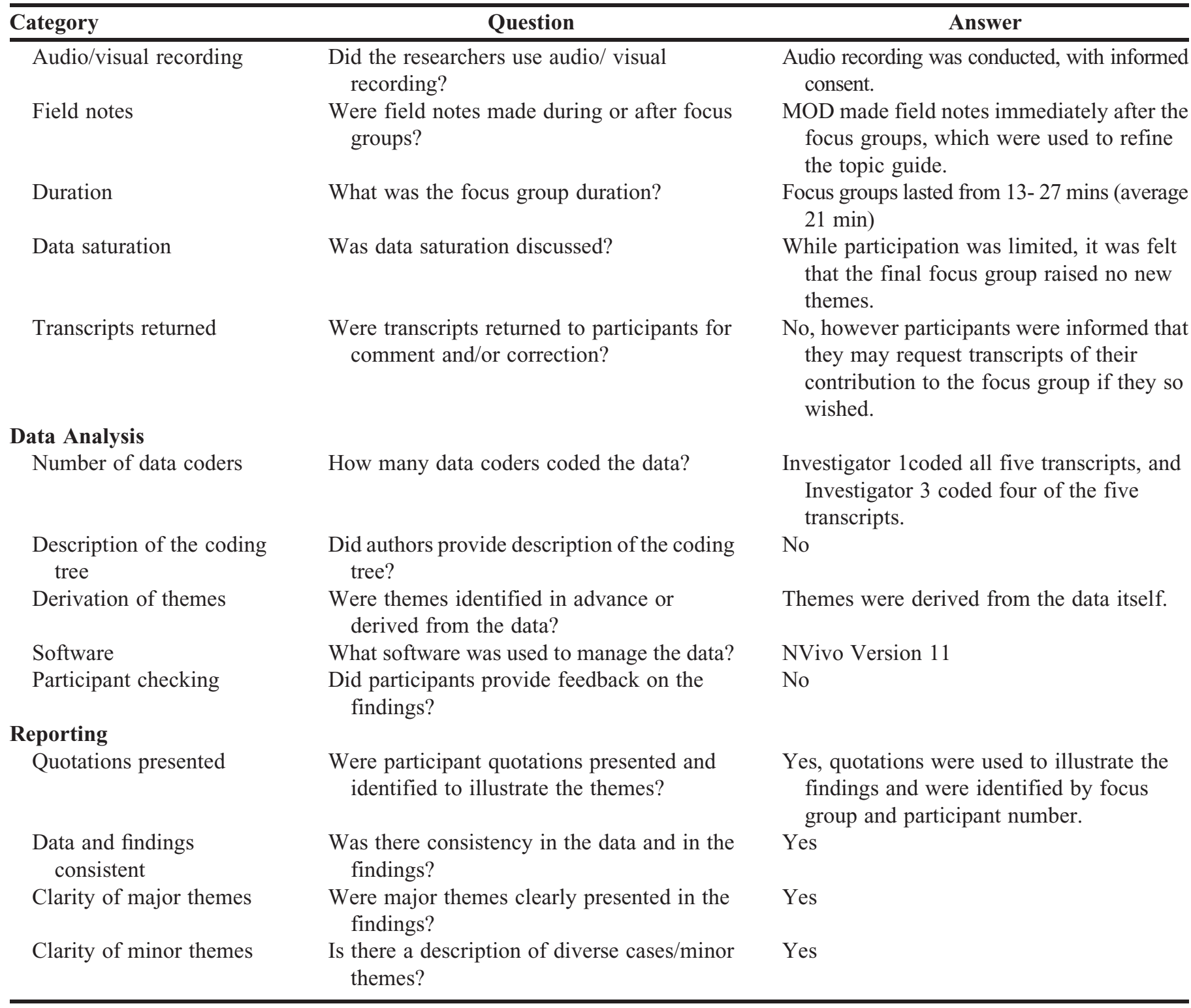




\section{American Journal of Pharmaceutical Education 2019; 83 (1) Article 6457.}

Appendix 2. Key Themes with Supporting Quotes from Focus Group Participants on Their Experiences of the Undergraduate Pharmacy Degree and the Potential Role of Mindfulness

Theme Time

The Role of the Lecturer

We're Smart People, We Want To Do Well
"I think definitely last year before Christmas a lot of people found it very hard. I can hear it in my voice already (emotional)... because a lot of people did find it very hard (emotional)... I know in my class alone several people were put, well got prescribed medications to cope with anxiety and stuff last year."

"Many times I used to cut down questions and predict stuff, hope it would come up...you just can't cover it all like, you can't cover everything!... you just hope to God this comes up and if it doesn't, you could end up repeating another year."

"Rent prices are only going up and it's more and more difficult...I'm lucky in that respect but I'm still aware that a lot of people have to pay their rent, they have to get their food so I mean a job at the weekends is pretty much the only thing. . . it might not be the best thing academically but financially it has to be done."

"I had to go at the weekend to work back home and I did it for ten weeks, and then I was off for a few weeks, and then I did it at Christmas time and I worked, maybe for two weeks. That cut straight into my study time and I ended up failing an exam over it."

"I know the lecturers are very accessible. They are very good to respond to your emails and stuff like that, but I just think that the time they have they're quite limited as well you know, so they can only do so much." (FG1, P3)

"I feel like they're only just in here to teach. . .I know it's trying to strike a balance between like their work, their own research work and their lecturing work."

"Like we're lucky that our lecturers, they are very good to us. . .but sometimes they're not always there, or sometimes you're not even close to your lecturers. . personally I'm not best friends with any lecturers so I don't feel like I can go to them and be like, express how I'm feeling to them."

"Not to get too deep or psychological about it but like to get into pharmacy you have to do so well in the Leaving Certificate. . .so that to come into college and to suddenly be not doing as well as you've always been doing is very tough. . .so I think you get so stressed by that complete flip of how well you perceive yourself to be doing."

"In general, we are very competitive people that go into courses like this, like we're smart people, we want to do well."

"I struggled to get into this course in the first place... now that I'm in it I don't want to let myself down, or I don't want to let my parents down, you know.. II don't want to disappoint people and I don't want to disappoint myself as well."

"In our course, we're taught very much to be critical about what we're doing and that can definitely, like I've seen it transpire into personal life, and people becoming very critical of themselves when they didn't need to be." (FG1, P4)

"Pharmacy is, I think, is it the second or third most sued profession? So when people kind of talk about that, kind of the idea that are we really mentally prepared to face a claim?"

"If you don't develop all your skills in like clinical you're going to kill someone... how do you deal with the fact that you're going to do that?... I don't think many of us would actually face that reality if it actually happened. Like it would ruin someone..."

"I think people procrastinate because they're afraid of failing. . .that fear of jumping in but then not actually being good enough anyway is just kind of scary." (FG4, P3)

"I generally like exams, I'm a really odd exception to any of these rules!...I mean you could be stressed out depending on the exam but I mean...there's only so much material and the lecturers will examine that, and there's only certain books that they look at and they will examine those books. . I'm never too stressed about them really" 


\section{American Journal of Pharmaceutical Education 2019; 83 (1) Article 6457.}

Appendix 2. (Continued)

$\begin{array}{ll}\text { Theme } & \text { Quotes }\end{array}$

Learning by Doing

"We did case studies and then they brought in patients. . and that was really helpful and we went through their health problems, and their dosages and everything that they were on. I thought the application of that was really good. Kind of hopefully I'll be doing more of that as I go on."

"When I started working in a pharmacy, it was most things you learn from dealing with customers. . .it's definitely preferential to work in a pharmacy, and you kind of almost need it to some extent, to prepare you for going into community pharmacy, you know."

Mindfulness as a Coping Tool

"My friend, like last year my housemate was having problems and I was trying to get her help and support and it wasn't easy at all, so like having the support within the pharmacy would be great."

"I think any module that would help you to develop your mental thinking with regards to the profession, people would be interested in it."

"Yeah it was interesting enough, it was basically just kind of just complete relaxation almost, just thinking about as little as possible."

"I think the more workshop-py (sic) tutorial type situations that we've done over the four years have definitely been more beneficial, you definitely learn a lot more."

"People don't want to be giving up half their lunch. . .unless you find gaps in people's timetables. . .you could just find a gap in the fourth year timetable, go with that, find a gap in second year..."

"Some people might see it as that you can't cope with the stress or something like that, that you're somehow like weaker. . .people could make that assumption like. . .instead of actually being an actually useful tool to help you cope with the rest of your career."

"If you told me this year, I'm going to give you a module on awareness, I'd be kind of like, "well I don't have time to go" you know?... just because we feel so under pressure with all those other things, I can see how people would be like "waste of time" even though I'm sure it could actually be very beneficial." 